\title{
Home Modification Outcomes in the Residences of Older People as a Result of Cougar Home Safety Assessment (Version 4.0) Recommendations
}

\author{
Grace S. Fisher, Laura Kintner, Erin Bradley, Diane Costulas, Jodi Kozlevcar, Karla Mahonski, \\ Keira McMenamin, Amanda Rompilla, Jillian Woods, Jay Stine, and Keith Ewonishon
}

\section{Misericordia University}

\begin{abstract}
The purpose of this study was to determine if recommendations made as a result of the administration of the Cougar Home Safety Assessment Version 4.0 (CHSA 4.0) were effective in causing older residents to make environmental safety modifications in their homes. Initial data were collected during the administration of the CHSA 4.0 in the homes of 40 older people in four northeastern states. After completing the initial assessments, the researchers provided the participants with recommendations for improving the environmental safety of their homes. Approximately one month later, each home was reassessed with the CHSA 4.0. Overall, improvement in environmental safety was demonstrated in the homes with the greatest increases being in fire safety, emergency phone number placement, and bathroom safety. A t-test demonstrated a significant gain in compliance $(t=7.8, p<.001)$ by comparing the difference between the mean initial and reassessment home safety scores. A very large effect size (Cohen's $d=1.7$ ) was also found, indicating a high magnitude of difference between initial and reassessment safety ratings. The assessment proved to be beneficial in increasing the environmental safety of homes.
\end{abstract}

(C) 2008 Californian Journal of Health Promotion. All rights reserved. Keywords: Home safety assessment, environmental safety, home accident prevention

\section{Introduction}

Every year, many older adults experience falls or other accidents in the home due to safety hazards. In an effort to address this problem, occupational therapy researchers at Misericordia University in Dallas, Pennsylvania developed an instrument called the Cougar Home Safety Assessment (CHSA 4.0) for measuring environmental safety in the homes of older people (Fisher, 2006; Fisher, Baker, Koval, Lishok, \& Stine, 2007; Fisher, Coolbaugh, \& Rhodes, 2006; Fisher, Civitella, \& Perez 2007; Fisher \& Ewonishon, 2007). The main purposes of this research study were to utilize the CHSA 4.0 to determine the level of environmental safety in the homes of older individuals, make appropriate safety recommendations, and then identify the extent to which the residents implemented the safety suggestions.
We contend that the CHSA 4.0 provides occupational therapists with a more detailed lens than the one that is customarily used to view potential safety hazards in the home. The CHSA 4.0 utilizes 78 criteria, which allow for examination of environmental features that extend beyond the usual scope of occupational therapy home care and community practice. For example, these added features address fire safety and disaster preparedness. Implementation of the CHSA 4.0 process, including evaluating the home and making safety recommendations, may be a valuable preventative occupational therapy service for older adults. Participation in this process may increase individuals' knowledge of safety hazards within their home and compel them to make environmental changes to increase safety. 


\section{Older People and Accidents in the Home}

In the U.S., injuries are one of the primary causes of fatality among the older population (Centers for Disease Control and Prevention (CDC), 2003). In 2001, an estimated 2.7 million older individuals experienced nonfatal injuries, with women suffering a higher percentage of these injuries than men (CDC, 2003). According to the CDC (2003), "the greatest number of nonfatal injuries among older adults were diagnosed as fractures (26\%), followed by contusions/abrasions (23\%), lacerations (17\%), strains/sprains (13\%), and internal injuries (5\%)." Of these nonfatal injuries, the most affected areas of the body were the neck and head, followed by the hands and arms (CDC, 2003). The CDC (2003) also found that only a small percentage of injured older adults $(16 \%)$ were hospitalized, and the majority $(82 \%)$ were released after being treated.

Numerous conditions may negatively affect the older adult population's level of safety in the home environment. These may include but are not limited to poor vision, arthritis, diabetes, poisoning, burns, crime, and depression. According to the United States Department of Health and Human Services, Agency for Healthcare Research and Quality, over $75 \%$ of individuals over the age of 65 live with one of these conditions (Agency for Healthcare Research, 2002). Many of these conditions lead to accidents around the house, including falls.

Diabetes can also lead to major safety issues in the home. This condition can hinder a person's ability to function as well as cause many secondary medical issues (Qui et al., 2006). Visual changes may also occur as a result of diabetes. Deficits in vision such as cataracts, macular degeneration, or blindness may be a serious risk factor for the older adult population in regard to home safety. Older adults may have difficulty ambulating safely throughout their households, making meals, and reading medication labels due to decreased vision. (Hinds et al., 2003).

Older patients who have conditions such as rheumatoid or degenerative arthritis may need to make environmental changes to their homes in order to ensure safety. The National Institute of Health (NIH) predicts that as the baby boomers continue to age, the prevalence of arthritis is also expected to rise since the risk of arthritis increases with age (NIH, 1998). Patients who have arthritis need to utilize different strategies to compensate for the manifestations of their condition, whether it is by keeping everything they need within easy reach or living on one floor of the house exclusively to avoid climbing stairs (Yoshida \& Stephens, 2004).

Older adults and young children are the two age groups most at risk for poisoning according to the Home Safety Council (2007). In a recent study, one in 10 caregivers of persons who were age 60 and over reported that an incident including poisoning occurred recently in the home (Home Safety Council, 2007). Ingestion, inhalation, injection, and absorption of harmful or potentially harmful substances are also risks faced by older adults. According to the American Association of Poison Control Centers, $92 \%$ of all poison exposures occur in the home (2002). Reasons for accidental poisonings include increased medication usage (often associated with prescriptions from more than one doctor), vision changes, sensory changes, and short-term memory loss (Children's Hospital of Philadelphia, 2007). Maintaining cleaning substances in their original packaging, storing cleaners and medications in locked cabinets, and keeping the poison control center phone number posted by the telephone are ways to reduce the risk of poisoning (Home Safety Council, 2007).

Carbon monoxide poisoning is often hard for health care providers to diagnose since symptoms resemble those of other chronic health conditions (Bekkedal, Sipsma, Stremski, Malecki, \& Anderson, 2006). Sources of carbon monoxide within the home include "car exhausts, central heating systems, open fires or barbecues, and tobacco smoke" with the "most common exposure sites being the kitchen and bathroom" (Harper \& Croft-Baker, 2004). The CDC (2008) reported greater death rates from carbon monoxide exposure for males and people over the age of 65 . 
Older housebound adults may be even more susceptible to carbon monoxide poisoning; furthermore, the problem may be hard to identify because its symptoms may mimic those of other medical conditions (Harper \& CroftBaker, 2004).

An investigation by Morbidity and Mortality Weekly Report found that $96.2 \%$ of severe poisonings during a power outage in Mecklenburg County, North Carolina occurred in residences that did not own a functioning carbon monoxide alarm (CDC, 2004). The study concluded the need for a law requiring a functioning alarm in all dwellings, "regardless of heating source and appliance type" (Harper \& Croft-Baker, 2004). Researchers and officials affiliated with the study hoped that these efforts would urge lawmakers in other communities to adopt a similar carbon monoxide poisoning prevention plan (Harper \& Croft-Baker, 2004).

As people increase in age they become vulnerable to household hazards. Safety imperfections that may have simply led to injury may cause more fatal results. Fires, in particular, are among the leading causes of death in the United States, third to falls and poisoning (National Fire Protection Association, 1996). According to the National Fire Protection Association (NFPA; 1996), this high rate of fires is due to "poor basic fire safety practices" and an inadequate number of residential smoke detectors.

According to the NFPA, an average of over 600 persons over the age of 75 die in fires each year (Stoil, 2005), and over 17,000 experience injuries secondary to residential fires (World Almanac, 2006). Cigarettes are currently the leading source of residential fires. In 2003 alone, cigarettes caused 25,600 structural fires in the United States (National Fire Protection Association, 2006). "Between 1999 and 2003, two-fifths ... of fatal smoking-material-fire victims were age 65 or older," and "almost half ... were sleeping when injured" (National Fire Protection Association, 2006).

Some of the most common injuries in the home are "scalds, contact burns, and chemical and electrical burns" (CDC, 2004). According to the National Burn Information Exchange, individuals over the age of 60 have the greatest overall risk of burns compared to any age group (The Burn Resource Center, 2002). The most common source of major burns in older adults is cooking in the kitchen (Ehrlich, 2006). Older adults are prone to such burns due to problems they may have with diminished reflexes and distractibility (Demling, De Santi, \& Orgill, n.d.). Candles also account for about 500 burn injuries in persons over the age of 65 (Hall, 2006).

Scald injuries are seen most commonly in kitchens and bathrooms. According to Demling, De Santi, and Orgill, (n.d.), major causes of scalds with older adults in the home include spilling hot liquids or moving containers that have extremely hot liquids. One strategy recommended to minimize scalds and burns is to keep hot items in the center of sturdy surfaces at least ten inches from the edge. The average time required to sustain a third degree burn at 155 degrees Fahrenheit is one second, versus five minutes at 120 degrees Fahrenheit. The maximal recommended temperature setting on water heaters to prevent injuries in the home is 120 degrees Fahrenheit; this high temperature is appropriate because as the water travels it will lose heat (Ehrlich, 2006).

The most frequent crime committed against older adults is property crime (Gesmond, Tafreshi-Darabi, Farkas, \& Rubin, 2005). Property crime includes burglary, property, and vehicle theft. In the year 2000, there were more than 18 million occurrences of property crime committed, of which $36 \%$ were reported to the police (Hart \& Rennison, 2003). According to the U.S. Department of Justice, adults over the age of 65 were "disproportionately affected by property crimes" and between the years of 1993 and 2002, nine out of 10 crimes against older adults involved property (Office of Justice Programs, 2006) According to the U.S. Department of Justice (2005), 93.1\% of the $32,133,480$ crimes committed against those 65 and older during the time period of 1993-2002 were property crimes involving burglary and theft. 
Older adults are more likely to face an attacker who targets them for robberies, thefts, and similar confrontations. These attackers are typically strangers. In order to make the home a safer place, it is recommended that all doors and windows be locked and secured with a strong mechanism that cannot be easily broken. In addition, an alarm system may also be beneficial for keeping the home secure. It is also important for older adults to get to know their neighbors so everyone in the community can look after one another (National Institute on Aging, 2006).

According to the Institute on Aging (n.d.), one person age 65 or older commits suicide every 83 minutes in the U.S.. Depression is often associated with suicide in older adults, but it is frequently undiagnosed. Older adults diagnosed with depression constitute two million of the 35 million older adults living in the United States (National Institute of Mental Health, 2003). According to the American Association for Geriatric Psychiatry, a greater number of older adults resort to firearms as a method of suicide in comparison to younger generations. Although a mental illness may be carefully managed, any firearm that is retained within the home is viewed as an increased risk factor for a suicide attempt. Possession of a loaded firearm in the home by an older adult diagnosed with mental illness may lead to a suicide attempt (Conwell, et al., 2002).

\section{Prevention of Falls}

In 2001, for persons 65 years and older, falls were the leading cause of home injury at 66 percent; poisoning and burns accounted for approximately $5 \%$ of the remaining hazards at home (Home Safety Council, 2006).

Falls are a major problem among the older adult population. Clemson et al. (2004) noted that a fear of falling or an incidence of a fall may increase the likelihood of feeling helpless and reduce confidence, resulting in decreased activity and mobility. Research has found that interventions that are educational and oriented toward changing behavior have had some success in preventing falls. Clemson et al. (2004) provided fall prevention training to older individuals through a community-based program called "Stepping On" (p. 1487). The "Stepping
On" program was conducted by an occupational therapist, who educated older adults on improving their strength, balance, and safety awareness in the home and community. The individuals who participated also had their vision tested and, if needed, adaptations were made to help with their poor vision so they could properly utilize the program. Their intervention program led to a $31 \%$ decrease in the number of falls. This study showed that a cognitivebehavioral approach entailing preventive education, visual aids, strength and balance building, and safety awareness training was one way to prevent falls in older adults.

A second study by Murphy and Tickle-Degnen (2001) looked at the way older persons who fear falling engage in daily activities. This study utilized 38 occupational therapists to analyze and grade activities for risk, and utilized data collected from 339 adults that had been a part of another longitudinal study conducted by Tennstedt et al. (2001). The occupational therapists ranked the activities according to the extent to which they challenged a person's balance (2001). It was found that as older adults became more inactive, their risk of falling increased. However, older adults with a routine were less likely to fall. The increased fall vulnerability of older people makes it imperative that they live in environments which are free of safety hazards.

Another study conducted by Diener and Mitchell (2005) investigated home safety and behavioral hazards and how they can be altered to decrease falls in the frail elderly. The study included 72 adults averaging 77 years of age (Diener \& Mitchell, 2005). All participants were involved in the adult day health care (ADHC) program. If they discontinued their attendance in ADHC, they were dropped from the study (Diener \& Mitchell, 2005). The participants were classified in groups according to the number of falls they had experienced in the last year. A home evaluation was then completed by an experienced physical therapist, followed by a letter with suggestions to decrease risks (Diener \& Mitchell, 2005). Various forms of intervention offered included a fall risk prevention demonstration, monthly newsletters, 
and phone calls discussing home modification (Diener \& Mitchell, 2005). Results showed a visible decline of $50 \%$ in environmental hazards for the experimental group (Diener \& Mitchell, 2005). The researchers concluded that with an increased awareness of health concerns and environmental hazards, falls can be greatly reduced (Diener \& Mitchell, 2005).

A study by Lord, Sherrington, and Menz (2001) found that the most common self-reported injuries among older people, such as bruises, cuts, and sprains, were the result of falls. Although falls are not a direct result of aging, the CDC notes that nearly half of all falls among the aging population occur within the home (CDC, 2002). Minor modifications to the environment can be made to help prevent such injury, for example, removing throw rugs or tacking them down, and installing grab bars in the bathroom (CDC, 2002). Grab bars can help ensure safety getting in and out of the bathtub and also rising from and sitting on the commode.

There are many options for fall prevention among older adults, but there is no research to identify which intervention strategy works the best (Whitehead et al., 2006). Whitehead et al. (2006) investigated the effectiveness of exercise classes, osteoporosis treatment, ceasing psychotropic medications, and home safety assessments on fall prevention. They found that home safety assessments led by an occupational therapist were more accepted and beneficial for people who have fallen before or have a fear of falling, as opposed to normal healthy individuals (Whitehead et al., 2006).

\section{Possible Risk Factors}

There are many risk factors for falling, foot problems being a commonly reported problem among older populations. Serious foot conditions in older people include bunions, ulcerations, and toe or nail problems, which can be accompanied by foot pain (Lord, Menz, \& Morris, 2006). Lord et al. (2006) examined foot problems such as these in older adults along with, "foot posture, foot range of motion, lesions, foot strength, foot sensation, and foot pain" (Lord et al., 2006, p. 867). Elderly people $(n=176)$ between the ages of 62 and 96 years of age living in a retirement village were studied to identify if these factors could be related to falling (Lord et al., 2006). Of the 176 respondents, 71 fell over a 12-month time span. The participants who fell exhibited "reduced ankle flexibility, more severe hallux valgus deformity, and reduced tactile sensitivity" (Lord et al., 2006). Further professional studies should be performed to validate the research completed in this particular study.

Mann, Locher, Justiss, Wu, and Tomita (2005) analyzed prior studies and found that the main causes for falls included: a decline in physical and mental status, hip weakness, a decrease in balance and mobility, the consumption of four or more types of medications, environmental obstacles, and poorly visible furniture. Mann et al. (2005) then showed evidence that using adaptive equipment for mobility may increase a person's susceptibility to falling. This study focused on home-based older adults to investigate possible differences between fallers and non-fallers; the investigation demonstrated that individuals with assistive devices were more likely to fall. However, both fallers and nonfallers were both physically frail, which may have contributed to falling in the first group (Mann et al., 2005).

Another study confirmed that the use of assistive devices may pose a risk for falling. According to McMillen and Söderberg (2002), every disabled person has a different reaction to assistive technology; therefore, occupational therapists and other professionals that prescribe these devices should be aware of the person's experience with the assistive devices. The purpose of their study was to gain knowledge of 15 persons' experiences with assistive devices in their everyday lives (McMillen \& Söderberg, 2002). Participants were interviewed in their own homes. They were asked to talk about which devices they used, how they used them, and also how their surroundings either helped or hindered the use of the equipment (McMillen \& Söderberg, 2002).

Genetics can be taken into consideration when considering the prevalence of falls. Pajala et al. (2006) conducted a study that looked at falls in 
older women to see if there was a genetic link. Sets of twins, both monozygotic and dizygotic, were used as the population for the study. These individuals signed a written consent form and then were instructed to use a calendar that was turned in each month to mark off the fall frequency. The study determined that familial factors accounted for susceptibility in falls, showing that a genetic factor in falls is still plausible (Pajala et al., 2006).

\section{Home Assessment and Modification}

According to Stark (2004), many older adults prefer to stay in their homes as they age because of emotional ties. However, environmental obstacles can become a threat to aging safely in their own home. Modifications to older adults' environments are important for maintaining their level of function, independence, and decreasing the need for moving to more accessible homes (Stark, 2004). Stark conducted a study which included 29 participants, all of whom were disabled and had low incomes. Through the use of home interviews and various measures, Stark measured the effects of architectural modification and adaptive equipment on occupational performance (Stark, 2004). During the home interviews, Stark utilized the Functional Independence Measure to determine the severity of the disability, the Canadian Occupational Performance Model to determine participants' occupational performance, and the Environmental Functional Independence Measure to identify environmental barriers (Stark, 2004). Together the occupational therapist and participants indicated goals and developed home modification plans. The occupational therapist who completed the initial interview went back to the homes of the participants 3 to 6 months later to complete a follow up analysis. He found that only 16 participants followed through with the recommended home modifications. The remaining 13 participants had not followed through for reasons such as not being completed by the agency, moving to a more accessible home, refusal of services, and inadequate physical construction of the home (Stark, 2004). The most common modifications made were the installation of handrails, grab bars, and ramps (Stark, 2004).
Individuals can continue to live safely within their homes if environmental modifications are performed. Tse (2005) took an in-depth look at studies of the impact of community and institutional environmental modifications performed between 1993 and 2004. Tse sought to help therapists better understand the effectiveness of environmental modifications to reduce falls and fall-related injuries in combination with other intervention approaches. Community setting studies found evidence to support that using at least one of three home modifications suggested by an occupational therapist greatly influenced the incidence of falls within the home (Tse, 2005). Common home modifications included installation of grab bars, use of shower seats, bath mats, and emergency alarms (Tse, 2005). When making these modifications in a community setting, it is important to remember family or caregiver perspectives, cost of modifications, and client compliance with much regard for client-therapist collaboration (Tse, 2005). These results showed that the sole use of environmental modifications is not as effective as when such modifications are combined with other intervention approaches such as exercise, education on fall prevention, and home modification follow-up (Tse, 2005).

Home assessments have proven to be effective in the past. Participants $(n=309)$, aged 75 years and older, were randomized into four groups (Campbell et al., 2005). Occupational therapists used the Westmead Home Safety Assessment Checklist to identify possible hazards, conducted one to two home visits, and completed a telephone follow up to identify and act upon possible hazards (Campbell et al., 2005). The homes were re-evaluated six months after they were initially assessed (Campbell et al., 2005). After the 12 months of testing, there was a $41 \%$ decrease in the number of falls in the home safety group in comparison to those who did not participate in the program (Campbell et al., 2005).

\section{Existing Occupational Therapy Assessment Tools}

The occupational therapy profession is in need of assessment tools which address the safety aspects of the home environment. A review of 
the American Occupational Therapy Association's Occupational Therapy Assessment Tools: An Annotated Index (Asher, 1996) yielded virtually zero assessments designed to directly address the environmental aspects of home safety. Of the 178 assessments mentioned by Asher, 21 assessments focused on activities of daily living (ADL) and home management. None looked at the environment to identify safety hazards. The existing assessments mentioned in the Index examine clients' safe performance of tasks, but not the physical features of the environment which may be placing people at risk for harm.

The researcher searched through a list of 222 common assessments found in Crepeau, Cohn, and Schell's (2003) Willard and Spackman's Occupational Therapy. The only assessment in the listing that specifically addressed home safety was the SAFER tool (Safety Assessment of Function and the Environment for Rehabilitation). Some other related assessments found were the Tinetti Assessment Tool, which focuses on the risk of falls in the elderly, the Housing Enabler, which covers limitations of using assistive devices and potential barriers inside or outside the home, and the Home Modification Workbook, which identifies architectural barriers in the home environment (Crepeau et. al, 2003).

An on-line search of all 2000 through 2006 issues of the American Journal of Occupational Therapy (American Occupational Therapy Association, AJOT Online, n.d.) for articles about home environmental safety assessments yielded none. While searching in AJOT on-line, the researcher used the following key words in hope of yielding reports about home safety: "home safety," "home safety assessments," "assessments," "environmental assessments," and "environment." When doing a search on The Misericordia University Bevevino Library's journal finder, EBSCO HOST, using the key words "home safety assessments," "occupational therapy," "elderly," "home safety," 26 results were yielded; only three assessments were found. These were the SAFER tool, the Safe at Home Assessment, and the Westmead Home Safety Assessment.
The Westmead Home Safety Assessment was named in a study published in Physical and Occupational Therapy in Geriatrics (McNulty, Johnson, Poole, \& Winkle, 2003). The Westmead Home Safety Assessment was also found in studies published in four other peer reviewed journals obtained by searching EBSCO HOST using the key words Westmead home, safety, and assessment. The Westmead Home Safety Assessment was created by Clemson (1997), and is a 72 item screening tool that occupational therapists use in order to identify home safety hazards that address structural or fixed features, use of space, natural and artificial lighting, color contrast, hallways, and pathways (McNulty, et al., 2003).

Other current occupational therapy home safety assessments were found in a book called ROTE: The Role of OT with the Elderly (Larson, Stevens-Ratchford, Pedretti, \& Crabtree, 1996). These were the Home Assessment Checklist for Fall Hazards and the Falls Interview Schedule. The Home Assessment Checklist for Fall Hazards (Cook \& Miller, 1996) is a comprehensive assessment tool which aims to prevent falls in the home. The home assessment checklist is comprised of 48 questions addressing a variety of environmental safety features. The evaluator is asked to respond to the questions by choosing Yes, No, DK (don't know), or NA (not applicable). The areas that are covered by the checklist are the home exterior and interior, and the kitchen, bathroom, and bedroom (Cook \& Miller, 199). The checklist does not address fire safety, medication management, or smoke and carbon monoxide detectors, which are all included in the Cougar 4.0 .

The Safe at Home Assessment is a standardized and function-based screening tool which determines the client's ability to identify and correct home safety problems (Robnett, Hopkins, \& Kimball, 2002). Robnett, Hopkins, et al. (2002), from the University of New England, developed the Safe at Home assessment. The first part of their study involved constructing 12 unsafe home situations. Next the clients were asked to identify the troublesome situations and describe how they would remedy 
them. Finally, the clients actually implemented the modifications to alleviate possible danger. The assessment, therefore, addresses safety awareness and judgment in the home environment.

The Safety Assessment of Function and the Environment for Rehabilitation Tool (SAFER), is a well known assessment tool utilized by occupational therapists (COTA, n.d.). The purpose of the SAFER is to measure a client's ability to safely function in his or her own home. The 94 item assessment is grouped into 14 main sections that view each area of the household in detail. These sections of the home address living situation, mobility, kitchen, fire hazards, eating, household, dressing, grooming, bathroom, medication, communication, wandering, memory aids, and general.

\section{Other Occupational Therapy Assessments}

The Gerontological Environment Modifications (GEM) Environmental Assessment: Apartment Safety and Design is a tool created by Rosemary Bakker (2005) of Cornell University Medical College. The GEM assessment identifies problems and possible solutions for each room in the house and the immediate outdoor area. The areas of the home covered by the GEM include the living room, bedroom, hallway, bathroom, kitchen, indoor stairs, outdoors, other, and follow up (Bakker, n.d.). Each section is made of detailed questions to which the user responds either yes or no. The GEM provides suggestions and possible modifications to remedy identified problems. The GEM outlines a follow-up procedure to see if problems were corrected. It also allows for the identification of barriers such as resident refusal, inadequate funding, and improper recommendations (Bakker, n.d.).

\section{The Cougar Home Safety Assessment Series} The Cougar Home Safety Assessment (CHSA) Series was created by graduate occupational therapy students at Misericordia University (prior to 2007 known as College Misericordia) under the advisement of Associate Professor Dr. Grace S. Fisher, Coolbaugh, and Rhodes (2006) developed and field-tested Version 1.0 of the Cougar Home Safety Assessment for Older
Persons (CHSA 1.0), an instrument which identified specific safety hazards in the homes of older people. The goal was to have a tool that "exclusively addressed the environment" (Fisher, Coolbaugh, \& Rhodes, 2006). Dr. Fisher explained (personal communication, April 1, 2007) that the reason for this environmental focus was to ensure that numerous aspects of home safety as they relate to home design, room and furniture arrangement, accessibility, and home maintenance would be addressed. She further noted that occupational therapists may often not have the resources they need to provide such a thorough assessment of the physical aspects of the home. It was hoped that the CHSA would become an effective resource for this purpose. Fisher, Coolbaugh and Rhodes (2006) conducted a field test in which they assessed 14 homes using the CHSA 1.0. Their study yielded $90 \%$ agreement between the three raters who assessed the homes. This is a significant amount of interrater reliability. The common safety violations found in the homes included "absence of grab bars by toilets, lack of emergency number postings, slippery rugs, inaccessible attics, and lack of fire extinguishers on every level of the home" (Fisher, 2006).

Version 2.0 of the Cougar Home Safety Assessment was devised and used to determine the level of safety in the homes of 44 older adults living alone in Pennsylvania and New Jersey (Fisher, Baker, Koval, Lishok, \& Stine, 2007). Overall, this study showed that there was a need for home safety assessments as preventative measures for assuring safe home environments. However, the older residents were limited in their ability to institute the safety recommendations, with financial constraints and inability to complete modifications being the drawbacks. Fisher et. al. determined that the participants' leading safety problem, as measured by the assessment, was the lack of carbon monoxide detectors on all floors of their homes. Their second most unsafe criterion was the lack of fire extinguishers on all floors. The researchers determined that fire risks were present in $19 \%$ of the residences they studied, while physical injury risks were observed in $8 \%$ and medical response risks were seen in $10 \%$. 
The 44 individuals in the CHSA 2.0 study lived alone, while those in the CHSA 1.0 study may have lived with others (Fisher, 2006). Seventyone percent of participants in the CHSA 1.0 study and $73 \%$ of those in the CHSA 2.0 study reported learning something new regarding home safety as a result of their involvement in the investigations (Fisher, 2006). Seventy-one percent of the CHSA 1.0 study participants (as compared to $61 \%$ of those in the CHSA 2.0 study) intended to make changes in their homes as recommended by the researchers as a result of the conducted assessment (Fisher, 2006). Expert advice gathered from other occupational therapists found the CHSA 1.0 and 2.0 to be user-friendly and practical (Fisher, 2006).

In order to aid in the prevention of injuries and to improve previous versions of the tool, the CHSA 3.0 was developed (Fisher et. al., 2006). This version was also used to aid occupational therapists in identifying hazardous situations within older adults' homes (Fisher, Cardillo et al., 2006). In the CHSA 3.0 there were nine categories which included, "(a) fire hazards/carbon monoxide, (b) emergency/medical, (c) electrical/water temperature, (d) flooring/hallways, (e) kitchen, (f) bedroom, (g) bathroom, (h) closets and storage areas, and (i) parking areas and entrances" (Fisher, Cardillo et al. 2006) safety criteria. There were a total of twenty participants in the CHSA 3.0 study. All of them were 65 years or older and independently lived in a house or apartment. Out of the 66 items tested, the absence of a smoke detector on every floor was the most prevalent problem found in the investigation (Fisher, Cardillo et al., 2006). In this study a total of 195 recommendations were made, with an average of nine adaptations suggested for each home. Follow-up visits to the homes of all twenty participants demonstrated that $53.84 \%$ of the safety recommendations were acted upon and fulfilled (Fisher, Cardillo, et al. 2006).

\section{Theoretical Base: Person-Environment- Occupation Model}

The CHSA instrument development studies conducted at Misericordia University are supported by the theory conceptualized in the
Person-Environment-Occupation (PEO) Model. The PEO Model described the interaction between an individual and the environment, and how adaptations are used to achieve desired occupational performance (Stewart, Letts, Law, Acheson-Cooper, Strong, \& Rigby, 2003).

Version 4.0 of the CHSA is a standardized tool a therapist may use to assess the environment of an older individual to ensure safety in the home. The safety of an environment can be enabling or inhibiting to the individual's occupational performance. Therefore, it is essential to adapt the environment to achieve optimal occupational performance (Stewart et al., 2003). This process may be facilitated through the use of the CHSA 4.0 .

\section{Literature Review Summary}

Pre-morbid conditions and hazards in the home are considerations when evaluating the safety of older adults. Hazards that affect older people within the home include non-fatal injuries, poisonings, residential fires, burns, property theft, weapon storage, disaster preparedness, and falls. Falls are a leading problem for those over the age of 50, not solely in the United States but throughout the world. Home modification is increasingly recognized for its importance as an effective means for improving safety.

\section{Method}

\section{IRB Approval}

Approval for this study was obtained through the College Misericordia (now known as Misericordia University) Institutional Review Board.

\section{Research Design}

This research project utilized a quantitative quasi-experimental research design. Eight graduate occupational therapy students assessed the safety of 40 residences using the CHSA 4.0. After gathering this information, the students then made recommendations for appropriate environmental modifications to the residences. Within one to two months the research team returned to re-evaluate whether safety modifications were made within each residence. 


\section{Participants}

Participants for this study were 40 men and women ages 50 years and older who resided independently in homes, apartments, senior high rises, mobile homes, or other types of residences in the community. The cut off age of 50 was chosen because typically in middle age, individuals begin to face the challenges of aging, which may render them more vulnerable to accidents and victimization in their homes. For example, in middle age visual changes may begin to become more pronounced, arthritic changes in the joints may result in pain and weakness, and weight gain may lead to a lowered level of physical fitness. The researchers surmised that these physical changes, coupled with complacency, may make some of these individuals less likely to adhere to recommended safety criteria in their home environments.

In order to participate in this study, the participants were required to have the cognitive ability to understand the various criteria of the CHSA 4.0, as demonstrated informally at the time of the initial contact with the researcher via interacting, answering questions, and showing an understanding of the need for safety assessment. Additionally, participants needed to be in good health and needed to have the functional ability to show the researchers their homes. This, too, was determined informally at the time of the initial contact. In order to obtain the participants, the researchers used convenience sampling. The participants were sought out through the community via personal connections; one participant was enlisted through the distribution of a flyer on campus.

\section{Informed Consent}

The participants reviewed and signed an informed consent form before the initiation of the study. The researchers thoroughly explained the consent form, the purpose of the study, and what it would entail to the potential participants.

\section{Instrumentation: \\ Demographics}

This research project gathered both qualitative and quantitative data. A demographic information sheet was used to collect information regarding the type of home, age, gender, state of residence, type of community, and employment status of the participants. Qualitative data consisted of the researchers' recordings of the recommendations that were made to each participant as part of the assessment process.

\section{Cougar Home Safety Assessment 4.0}

The CHSA 4.0 was designed to cover different environmental features important for safety in the home. The CHSA 4.0 contains 78 home safety criteria which served as the basis for the assessments. The main categories that it addressed for potential safety modifications were: fire hazards/carbon monoxide detection, emergency/medical resources, electrical/water temperature, flooring/hallways, kitchen, bathroom(s), clothes/storage areas, parking area/entrances, bedroom, and disaster preparedness. Tools required to complete the assessments were a flashlight, a yardstick, a thermometer, and a pen. Administration of the assessment takes approximately one hour in the home. At the conclusion of each assessment the researchers provided participants with written recommendations. If the assessment identified the need for adaptive equipment or environmental aids or devices, the participants were provided with instructions on where to purchase the items.

\section{Data Collection}

Data that were collected corresponded with each of the 78 criteria of the CHSA 4.0. They included each criterion's rating as either "environment safe" or "environment unsafe", along with the home safety modification recommendations that were ultimately made to each participant. Additional data were the calculated home safety scores (ranging from a possible 0 to 100) for each participant's residence. These were determined according to the instructions stated in the CHSA 4.0 instrument. A home safety score of 100 indicated that the residence was rated safe across all 78 criteria. A coding system was used to record all data, so that participant confidentiality was maintained. The researchers were the only people who had access to the code. 


\section{Data Analysis}

The graduate students entered the data into the Statistical Program for Social Services version 15.0 (SPSS). Safe and unsafe ratings were entered into SPSS for each resident.

Descriptive statistics, including percentages and means, were calculated across all criteria and across all residences. Using inferential statistics, the percentage of homes rated "environment safe" and "environment unsafe" for each of the 78 criteria during the initial assessment were statistically compared with the safety percentages obtained during the re-assessment visits.

Individual overall safety scores were entered into SPSS for each resident. A p-value of .05 was set, indicating that the researchers were interested in seeking a $95 \%$ level of confidence that the CHSA 4.0 had a significant effect on the participants' follow-through with the researchers' home safety recommendations.

\section{Research Rigor}

Prior studies involving the CHSA series testify to the validity of the assessment (Fisher, Baker, et al. 2007; Fisher, Cardillo, et al. 2006; Fisher, Coolbaugh, et al., 2006; Fisher, 2006). A recent study by Fisher, Civitella, and Perez (2007) substantiated the content validity of the CHSA 4.0 specifically, and led to its refinement, via a Delphi survey. A recent nationwide investigation also more rigorously examined the content validity of each of the criteria of the CHSA 4.0, by surveying a larger sample of occupational therapists who were familiar with this practice area (Fisher \& Ewonishon, 2007).

\section{Results}

\section{Participant Demographics}

Demographic data for the participants is displayed in Table 1. The participants were predominantly female and represented a broad range of older adults from ages 50 to 96 . Participant homes varied in their type, and represented urban, suburban, and rural settings.
Table 1

Participant Demographic Characteristics $(n=40)$

\begin{tabular}{|c|c|c|}
\hline \multicolumn{3}{|c|}{ Gender } \\
\hline & Frequency & Percent \\
\hline Male & 14 & 35 \\
\hline Female & 26 & 65 \\
\hline \multicolumn{3}{|c|}{ Age } \\
\hline $50-59$ & 16 & 40 \\
\hline $60-69$ & 12 & 30 \\
\hline $70-79$ & 9 & 22.5 \\
\hline $80-89$ & 2 & 5 \\
\hline $90+$ & 1 & 2.5 \\
\hline \multicolumn{3}{|c|}{ State of Residence } \\
\hline $\mathrm{CT}$ & 1 & 2.5 \\
\hline NJ & 3 & 7.5 \\
\hline NY & 5 & 12.5 \\
\hline PA & 31 & 77.5 \\
\hline \multicolumn{3}{|c|}{ Community } \\
\hline Rural & 16 & 40 \\
\hline Suburban & 20 & 50 \\
\hline Urban & 4 & 10 \\
\hline \multicolumn{3}{|c|}{ Home } \\
\hline Apartment & 2 & 5 \\
\hline Ranch & 10 & 25 \\
\hline Split-Level & 4 & 10 \\
\hline Two-Story & 23 & 57.5 \\
\hline Other & 1 & 2.5 \\
\hline \multicolumn{3}{|c|}{ Employment } \\
\hline Working & 19 & 47.5 \\
\hline Retired & 19 & 47.5 \\
\hline Unemployed & 1 & 2.5 \\
\hline Other & 1 & 2.5 \\
\hline
\end{tabular}

\section{Mean Percent of Residences Rated "Safe" at Initial and Reassessment and Mean Improvement}

At the time of the initial assessment there was $100 \%$ compliance with 20 of the CHSA 4.0 criteria. These included keeping flammable objects away from fire sources, walkways free of clutter, and electrical cords in good condition. There were also a significant number of criteria that did not achieve $100 \%$ compliance, but there was very high safety compliance at the time of initial assessment. Obviously there was little if any room for improvement for criteria which had these high initial scores. Criterion number 
19, for example, maintained a score of 95 throughout initial and final assessment.

There were 58 criteria for which one or more ratings were "unsafe" at the time of the initial assessment. Of these 58, 10 showed no improvement between initial assessment and reassessment. The 10 criteria which demonstrated no improvement at the time of re-assessment, along with the 20 which were initially rated as safe for $100 \%$ of the participants (and therefore could not demonstrate further improvement) are illustrated with white background shading in Table 2. Additionally, 38 of the 58 criteria showed some improvement (defined as 1-14 point improvement) at the time of re-assessment, and are shown in the areas of Table 2 which have a light gray background. Finally, 10 of the 58 criteria demonstrated great improvement (defined as $15-35$ point improvement) at the time of the re-assessment, and these are shown in the areas of Table 2 which have a dark gray background.

The 10 criteria with the lowest safety ratings at the time of the initial assessment were \#69disaster kit readily available (85\% unsafe), \#71copy of medication in a sealed plastic bag and placed in the disaster kit (65\% unsafe), \#77emergency car kit available for evacuation $(65 \%$ unsafe), \#5-carbon monoxide detectors tested within the last six months (55\% unsafe), \#76clothes and shoes available for immediate use during disasters and emergencies (52.5\% unsafe), \#44-the following bathroom areas are accessible and may be reached without significant risk of physical injury and they are bathtub, toilet and sink (45\% unsafe), \#24ground fault switches are present in bathroom and kitchen outlets (42.5\% unsafe) , \#46-a properly installed grab bar or other stable surface is available and secure near the tub and toilet (40\% unsafe), \#12-emergency numbers are posted on or near the telephone or are easily accessible without risk of injury (35\% unsafe), and \#30-if throw rugs are present, they have slip resistant backing (32.5\% unsafe).

Improvement was noted in 48 criteria, with ten of the areas showing significant change. The greatest improvement in safety was a 35 point gain for having a fire extinguisher present on every frequently used floor of the home. Having emergency phone numbers posted and a slipresistant mat outside the bathtub both improved 30 points at the time of reassessment. Furthermore, some participants added carbon monoxide detectors, increasing their compliance with this criterion by 28 points. Some individuals had these detectors tested, improving their compliance with this criterion by 25 points. Individuals that were tested added resistant backing to throw rugs and included medication in their disaster kits, increasing these standards of compliance by 18 points. Criteria which improved by 15 points were adding night lights, creating disaster kits, and including a copy of current medications in wallets.

Table 3 displays the overall improvement in each participant's safety score. Eleven participants had a 10-point or higher increase in their overall safety scores between the initial assessment and reassessment. An additional eleven participants demonstrated between five and nine points improvement at the time of reassessment. Fifteen participants demonstrated between one and four points of improvement, and three showed no improvement. The average increase in safety score for the 40 residences was seven points, with the initial mean safety score at $85 \%$ and a reassessment mean safety score of $92 \%$.

\section{Statistical Significance and Effect Size}

This study utilized repeated measures and was nonparametric; however, warranted by the sample size $(\mathrm{n}=40)$, a t-test was employed to compare the pretest and posttest scores. The overall mean improvement in scores was approximately 6.4, with an approximate standard deviation of $5.2(\mathrm{t}=7.8, \mathrm{p}<.001)$. Thus, statistical parameters showed that the gains in safety compliance made between initial and reassessment were highly significant, and were much more significant than the .05 p-value criterion for statistical significance. By virtue of the t-test for statistical significance, Cohen's d was calculated as the appropriate measure of effect size (Cohen, 1988). An effect of .8 or greater is considered to be large (Portney \& Watkins, 2000). A very large effect size $(d=$ 
1.7) was achieved in this study, indicating a high degree of positive change between initial and reassessment ratings.

\section{Discussion}

This study's findings are indicative of the CHSA 4.0's effectiveness as a tool for facilitating large positive environmental safety changes in the residences of older adults.

Through the data analysis, it became evident that certain safety criteria improved while others remained the same from initial assessment to reassessment. Certain safety criteria were easier to modify, therefore improving the participants' safety scores. On the other hand, other criteria were initially safe, thus requiring no changes. In reviewing the improvements which were actually made as a result of the recommendations, smoke detectors were a more likely investment than criteria which involved modifications to the structure of the home. This may have been influenced by monetary limitations, time restrictions, and apathetic thoughts about the importance of home modifications, denial of possible safety hazards, and other personal reasons.

The CHSA 4.0 is a universal tool which can potentially be utilized in many occupational therapy practice settings such as assisted living, outpatient rehabilitation, home healthcare, psychiatric settings, community wellness, and consultation with architects and home designers. Community wellness programs may utilize this tool in order to increase the awareness of potential safety hazards in the homes of the well-elderly.

According to Johansson (2000), design and accessibility consulting and home modification, private practice community health services, and health and wellness consulting are among the top ten emerging areas of occupational therapy practice for the new millennium. The CHSA 4.0 could be useful in each of these three practice areas, promoting universal design, assisting with fall prevention, and encouraging environmental modification.
Within the next decade, over 52 million people in the United States will be over the age of 65 and approximately seven million people will be 85 years old (Painter \& Elliott, 2004). This group of 52 million will include many of the participants in this study, some of whom were age 50-something at the time of this investigation. As the average age of the "babyboomers" increases, so does the need for health promotion and prevention within the community. It is imperative for occupational therapists to promote health and well-being now and in the near future. The state of North Carolina, for example, has established a community based program funded by local hospitals called the SPICE for Life Program. This series of seminars provides "communitybased education sessions to seniors, caregivers, and health care professionals on fall prevention, home safety, memory and normal aging, and care giving for those with Alzheimer's disease" (Painter \& Elliot, 2004 p. 55). Occupational therapists need to increase their involvement in community based programs such as this, as they are important and valuable methods of providing community education.

\section{Limitations}

Limitations of this investigation included the relatively small geographic region of the study, with participant residences limited to Pennsylvania, New York, New Jersey and Connecticut. There were also a relatively small number of participants involved in the study. Furthermore, the financial status of these individuals could have limited whether or not they made the safety changes to their residences. Although multiple types of private participant residences were assessed in this study, the investigation did not include communal residences such as accommodations in assisted living facilities or senior high rise apartments. Another limitation of the study was the relatively short period of time between initial assessment and reassessment. If the participants had been given more time they may have been able to make more extensive safety changes in their homes. Inter-rater reliability was also a limitation of this study because of the number of student researchers conducting the assessments. 
The ages of the participants also may have been a limiting factor. Younger individuals between the ages of 50 and 65 may have been more able and willing to make the recommended changes in their homes, while older individuals may have had less capability and motivation to make the modifications.

\section{Recommendations}

There are many recommendations to consider for future studies. A reasonable period of time between initial assessment and reassessment is suggested to assure that the client can make the necessary changes. A resource list including the costs and availability of pertinent home modifications may also prove beneficial for greater compliance with implementation. In future studies, the assessment should be made available to individuals with physical impairments or disabilities, such as hearing impairments. In addition, occupational therapists who use the CHSA 4.0 may choose to perform the reassessment over the phone if they are unable to schedule a second home visit due to time and/or location constraints; self-assessment by residents may also be considered for the same reasons. Finally, more research on the use and effectiveness of the CHSA 4.0 is recommended to continue to validate its efficacy as a remediation tool.

\section{Conclusion}

The results of this study suggest that the CHSA 4.0 is a useful tool for increasing home safety for older adults. The success of this study indicates that older adults are interested in acquiring knowledge regarding home safety modifications and accident prevention. This investigation demonstrated the need for occupational therapy involvement in increasing home safety. Through client education using the
CHSA 4.0, occupational therapists promote independence and prevent potentially harmful accidents. The CHSA 4.0 is a comprehensive home assessment which serves as an effective and thorough tool. It is available for downloading from the Misericordia University Occupational Therapy Department website at: http://www.misericordia.edu/misericordia_pg_s ub.cfm?sub_page_id=935\&subcat_id=108\&pag e_id=338.

Occupational therapists are encouraged to utilize the assessment in practice, and to communicate any comments and feedback concerning the usefulness of the assessment to the researchers. Occupational therapists who are experienced in home care will require no additional training to use the assessment, however, they are encouraged to carefully review the assessment instructions and scoring directions it offers. Occupational therapists are also encouraged to review the Cougar Home Safety Assessment Series instrument development studies, cited in this report, which were conducted by Fisher and her occupational therapy graduate students.

\section{Acknowledgements}

The authors acknowledge the prior research groups for their work on the CHSA, and the 40 participants who welcomed us into their homes. In addition, the authors acknowledge the contributions made by our research committee reader Dawn Evans, Occupational Therapy Fieldwork Coordinator, Misericordia University.

\section{Dedication}

This report is dedicated to the memory of Megan Delaney, former classmate of Grace Fisher, both graduates of Dallas High School Class of 1974. Megan tragically lost her life in a fire in her home in February of 2008. 


\section{References}

Agency for Healthcare Research and Quality (2002). Preventing Disability in the Elderly With Chronic Disease. Research In Action, (3). AHRQ Publication No. 02-0O18, Retrieved September 10, 2008, from http://www.ahrq.gov/research/elderdis.htm.

American Association of Poison Control Centers. (2002). Quick facts on poison exposures in the United States. Retrieved February 19, 2007, from http://www.1-800-222-1222.info/stats/home.asp

American Occupational Therapy Association (n.d.). American Journal of Occupational Therapy [Online]. Retrieved November 16, 2006, from http://www.aota.org/ajot/backissue.asp

Asher, I.E. (1996). Occupational therapy assessment tools: An annotated index. Bethesda, MD: American Occupational Therapy Association.

Bakker, R. (n.d.). Gerontological environmental modifications: Environment assessment apartment safety \& design. Retrieved on October 28, 2006, from http://environmentalgeriatrics.com/pdf/enviro_assessment.pdf.

Bekkedal, M., Sipsma, K., Stremski, E.S., Malecki, K.C., \& Anderson, H. A. (2006). Evaluation of five data sources for inclusion in a statewide tracking system for accidental carbon monoxide poisonings. Wisconsin Medical Journal, 105, 36-40.

Campbell, A.J., Robertson, M.C., La Grow, S.J., Kerse, N.M., Sanderson, G.F., Jacobs, R.J. (2005). A preventative home safety program for community-dwelling older people with low vision reduced falls and was more cost-effective than an exercise program. British Medical Journal, 331, 243244.

Centers for Disease Control and Prevention. (2004). Use of carbon monoxide alarms to prevent poisonings during a power outage - North Carolina, December 2002. Morbidity and Mortality Weekly Report, 53, 189.

Centers for Disease Control and Prevention. (2002). Preventing falls among seniors. Retrieved August 16, 2008, from http://www.cdc.gov/ncipc/duip/spotlite/fall tips.htm\#2.

Centers for Disease Control and Prevention. (2003). Public health and aging: Nonfatal injuries among older adults treated in hospital emergency departments - United States, 2001. Retrieved March 25, 2007, from http://www.cdc.gov/mmw R/preview/mmwrhtml/mm5242a4.htm

Centers for Disease Control and Prevention (2008). Non-fatal, Unintentional-Non-Fire Related Carbon Monoxide Exposures, United States 2004-2006. Morbidity and Mortality Weekly Report. 57, 896899. Retrieved September 24, 2008, from http://www.cdc.gov/mmwr/preview/mmwr $\mathrm{html} / \mathrm{mm} 5733 \mathrm{a} 2 . \mathrm{htm} ? \mathrm{~s} \_\mathrm{cid}=\mathrm{mm} 5732 \mathrm{a} 2$ e

Children's Hospital of Philadelphia. (2007). The elderly and poison prevention. Retrieved February 25, 2007, from http://www.chop.edu/consumer/jsp/divison/generic.jsp ?id =70995

Clemson, L., Cumming, R. G., Kendig, H., Swann, M., Heard, R., \& Taylor, K. (2004). The effectiveness of a community-based program for reducing the incidence of falls in the elderly: A randomized trial. Journal of the American Geriatrics Society, 52, 1487-1494. Retrieved September 25, 2006, from EBSCO host database.

Cohen, J. (1988). Statistical Power Analysis for the Behavioral Sciences (2nd ed.). New Jersey: Lawrence Erlbaum Associates, Inc.

Conwell, Y. (2007). Suicide in older adults: Management and prevention. Psychiatric Times, 24, 1-2. Retrieved March 11, 2007, from http://www.psychiatrictimes.com/Suicidal-Behavior/show /Article .jhtml?articleID=196901880

Conwell, Y., Duberstein, P. R., Connor, K., Eberly, S., Cox, C., \& Caine, E. D. (2002).Access to firearms and risk for suicide in middle-aged and older adults. American Journal of Geriatric Psychiatry, 10, 407-416. Retrieved March 11, 2007, from http://ajgponline.org/cgi/content/ abstract/10/4/407? maxtoshow=\&HITS=10\&hi+0\&RESULTFORMAT=\&searchid=1\%FIRSTIN DEX $=0 \&$ sortspec $=$ relevancevolume $=10 \&$ firstpage $=407 \&$ resourcetype $=$ HWCIT

Cook, A., \& Miller, P. (1996). Prevention of Falls in the Elderly. In K. Larson (Ed.) ROTE: The Role of Occupational Therapy with the Elderly (pp. 664-666). Bethesda, MD: American Occupational Therapy Association, Inc. 
COTA - Comprehensive Rehabilitation and Mental Health Services. (n.d.). SAFER TOOL /Safety Assessment of Function and the Environment for Rehabilitation Manuel. Toronto: COTA Comprehensive Rehabilitation and Mental Health Services.

Diener, D. \& Mitchell, J. (2005). Impact of a multifactorial fall prevention program upon falls of older frail adults attending an adult health day care center. Topics in Geriatric Rehabilitation, 2, 247257. Retrieved September 30, 2006, from CINAHL PLUS with Full Text database.

Fisher, G. (2006). Field Tests of the CHSAs for Older Persons Versions 1.0 and 2.0: Inter-rater reliability, content validity, and findings. An invited publication for a yearbook. Research and Practice in Alzheimer's Disease and Cognitive Decline, 11, 306-315.

Fisher, G., Baker, A., Koval D., Lishok, C., and Stine, E. (2007). Field test of the Cougar Home Safety Assessment (Version 2.0) in the homes of older person living alone. Australian Journal of Occupational Therapy, 54, 124-130.

Fisher, G.S., Cardillo, N., Chin, S., Derrick, E. \& Zepherin, K. (2006). Cougar Home Safety Assessment Version 3.0 for Community Dwelling Older Adults: Recommendations and Follow-Up. Unpublished manuscript, College Misericordia, Dallas, Pennsylvania.

Fisher, G., Coolbaugh, K., \& Rhodes, C. (2006). A field test of the Cougar Home Safety Assessment for Older Persons Version 1.0. California Journal of Health Promotion, 4, 181-196. Retrieved September 21, 2006, from http://www.cjhp.org/

Fisher, G., Civitella, H., \& Perez, V. (2007). A modified Delphi survey of the content validity of the Cougar Home Safety Assessment Version 4.0. Unpublished manuscript, College Misericordia, Dallas, Pennsylvania.

Fisher, G. \& Ewonishon, K. (2007). A survey of the content validity of the Cougar Home Safety Assessment Version 4.0. Unpublished manuscript, College Misericordia, Dallas, Pennsylvania.

Gesmond, S. A., Tafrehshi-Darabi, N., Farkas, B. L., \& Rubin, R. T. (2005). McKeesport aging program: A 3-year survey. FBI Law Enforcement Bulletin, 74, 26-32. Retrieved January 14, 2007, from Academic Search Premier database.

Harper, A., \& Croft-Baker, J. (2004). Carbon monoxide poisoning: Undetected by both patients and their doctors. Age and Ageing, 33, 105-109.

Hart, T. C. \& Rennison, C. (2003). Reporting crime to the police, 1992-2000. Retrieved January 14, 2007, from http://www.ojp.usdoj.gov/bjs/pub/pdf/rcp00.pdf

Hinds, A., Sinclair, A., Park, J., Suttie, A., Paterson, H., \& Macdonald, M. (2003). Impact of an interdisciplinary low vision service on the quality of life of low vision patients. British Journal of Ophthalmology, 87, 1391-1396. Retrieved February 3, 2007, from EBSCO host database.

Home Safety Council. (2006). Older adults and home injuries. Washington, DC: Home Safety Council. Retrieved December 4, 2006, from http://www.homesafetyco uncil.org

Home Safety Council. (2007). Home Safety Council research shows majority of households are unprepared to prevent poisoning injuries. Washington, DC: Home Safety Council. Retrieved September 1, 2008, from http://www.poisonprevention.org/pdf/PoisonPreventionRelease 33.16.07.pdf

Institute on Aging. Suicide \& the elderly. Retrieved September 25, 2008 from http://www.ioaging.org/services/counseling_healing/elderly_suicide.aspx

Johansson, C. (2000). Top 10 emerging practice areas to watch in the new millennium. Retrieved February 17, 2008, from http://www.aota.org/Practitioners/Practice Areas/Emerging/36247.aspxl

Larson, K., Stevens-Ratenford, R., Pedretti, L., \& Crabtree, J. (Eds). (1996). ROTE:The Role of Occupational Therapy with the Elderly. (2nd Ed.). Bethesda, MD:American Occupational Therapy Association, Inc.

Lord, S. R., Menz, H. B., \& Morris, M. E. (2006). Foot and ankle risk factors for falls in older people: A prospective study. Journals of Gerontology Series: A Biological Sciences \& Medical Sciences, 61A, 866-870.

Lord, S. R., Sherrington, C., \& Menz, H. B. (2001). Falls in older people: Risk factors and strategies for prevention. United Kingdom: Cambridge University Press. 
Mackenzie, L., Byles, J., \& Mishra, G. (2004). An occupational focus on falls with serious injury among older women in Australia. Australian Occupational Therapy Journal, 51, 144-154. Retrieved September 17, 2006, from http://www.blackwell-sunergy.com/doi/abs/10.1111/j.440-1630. 2004 $.00424 . x$ ? journalcode $=$ aot

Mann, W. C., Locher, S., Justiss, M. D., Wu, S., \& Tomita, M. (2005). A comparison of fallers and nonfallers in the frail elderly. Technology \& Disability, 17, 25-32. Retrieved September 17, 2006, from http://libproxy.misericordia.edu:3729/ehost.pdf?vid=3\&hid=120\&sid=c3bbb9d6-567a-484f -b2ba-7561aaf5d9b2\%40 session mgr109

McMillen, A. M. \& Söderberg, S. (2002). Disabled persons' experience of dependence on assistive devices. Scandinavian Journal of Occupational Therapy, 9, 176-183. Retrieved October 1, 2006, from http://libproxy.misericordia.edu:3729/ehost/pdf?vid=3\&hid=109\&sid=b7d0c6a6-b86d-4ecf91c1-85065d82de2b \%40 sessionmgr102

McNulty, M.C., Johnson, J., Poole, J.L., \& Winkle, M. (2003). Using the transtheoretical model of change to implement home safety modifications with community dwelling older adults: An exploratory study, Physical \& Occupational Therapy in Geriatrics, 21, 53-66.

Murphy, S., \& Tickle-Degnen, L. (2001). Participation in daily living tasks among older adults with fear of falling. American Journal of Occupational Therapy, 55, 538-544.

National Fire Protection Association. (2006). Fast facts. National Fire Protection Association. Retrieved February 10, 2007, from http://www.nfpa.org.

National Fire Prevention Association. (2002). NFPA: Fire deaths in homes dropped more than 9 percent in 2001. Fire engineering. Retrieved February 1, 2007, from EBSCOhost database.

National Fire Protection Association. (1996). National fire prevention week. Morbidity \& Mortality Weekly Report, 45, 813. Retrieved February 1, 2007, from EBSCOhost database.

National Institute of Mental Health. (2003). Older adults: Depression and suicide facts. Retrieved March 11, 2007, from http://www.nimh.gov/publicat/elderlydep suicide.cfm

National Institutes of Health (1998). Arthritis Prevalence Rising as Baby Boomers Grow Older. Retrieved September 12, 2008 from http://www.cfids-cab.org/wong/fmsprev.htm

National Institute on Aging. (2006). Crime and older people. Retrieved March 25, 2007 from http://www.niapublications.org/agepages/crime.asp

Office of Justice Programs. (2006a). National crime victimization survey property crime trends, 19732005. Retrieved January 14, 2007, from http://www.ojp.usdoj.gov/bjs/glance/tables/prop trdtab.htm

Office of Justice Programs. (2006b). Victim characteristics. Retrieved January 14, 2007, from http://ww w.ojp.usdoj.gov/bjs/cvict_v.htm

Painter, J., \& Elliot, S. (2004). Meeting community-dwelling older adults' needs through community education programs. Physical \& Occupational Therapy in Geriatrics, 22, 53-66. Retrieved February 17, 2008, from Academic Search Premier database.

Pajala, S., Era, P., Koskenvuo, M., Kaprio, J., Viljanen, A., \& Rantanen, T. (2006). Genetic factors and susceptibility to falls in older women. Journal of the American Geriatric Society, 54, 613-618.

Portney, L.G., \& Watkins, M.P. (2000). Foundations of clinical research- Applications to practice (2nd ed.). Upper Saddle River, New Jersey: Prentice Hall Health.

Qiu, W. Q., Price, L. L., Hibberd, P., Buell, J., Collins, L., \& Leins, D. et al. (2006). Executive dysfunction in homebound older people with diabetes mellitus. Journal of the American Geriatrics Society, 54, 496-501. Retrieved February 3, 2007, from CINAHL PLUS with Full Text database.

Robnett, R.H., Hopkins, V., \& Kimball, J.G. (2002). The Safe at Home: A quick home safety assessment. Physical and Occupational Therapy in Geriatrics, 20, 77-101.

SPSS Inc. (2006). SPSS base for Windows (version 15.0) [Computer software]. Chicago, IL: SPSS Inc.

Stark, S. (2004). Removing environmental barriers in the homes of older adults with disabilities improves occupational performance. OTJR: Occupation, Participation and Health, 24, 32-39. Retrieved September 25, 2006, from CINAHL PLUS with Full Text database. 
Stevenson, J. (2005). Alcohol use, misuse, abuse, and dependence in later adulthood. Annual Review of Nursing Research, 23, 245-280. Retrieved February 3, 2007, from the CINAHL PLUS with Full Text database.

Stewart, D., Letts, L., Law, M., Acheson-Cooper, B., Strong, S., \& Rigby, P.J. (2003). The PersonEnvironment-Occupation Model. In E.B. Crepeau, E. S. Cohn, \& B.A.B Schell (Ed.s), Willard \& Spackman's occupational therapy,10th ed.,(pp.227-223). Philadelphia: Lippincott, Williams \& Wilkins.

Stoil, M. (2005). Where there's smoke. Nursing Homes: Long Term Care Management, 54. Retrieved February 9, 2007, from EBSCOhost database.

The National Shooting Sports Association, Inc. (2006). Firearms responsibility in the home. Retrieved March 20, 2007, from http://www.remington.com/pdfs/ safety/firearmsresphome.pdf

Tse, T. (2005). The environment and falls prevention: Do environmental modifications make a difference? Australian Occupational Therapy Journal, 52, 271-281. Retrieved September 16, 2006, from EBSCOhost database.

United States Department of Justice (2005). NCJ 206154. Special report: Crimes against persons age 65 or older, 1993-2002. Retrieved September 24, 2008, from http://www.ojp.usdoj.gov/bjs/pub/pdf/ cpa6502.pdf

Vu, H., Keeffe, J., McCarty, C., \& Taylor, H. (2005). Impact of unilateral and bilateral vision loss on quality of life. The British Journal of Ophthalmology, 89, 360-363. Retrieved February 3, 2007, from MEDLINE database.

Whitehead, Craig H., Wundke, R., \& Crotty, M. (2006). Attitudes to falls and injury prevention: What are the barriers to implementing falls prevention strategies? Clinical Rehabilitation, 20, 536-542. Retrieved October 2, 2006, from EBSCOhost database.

World Almanac \& Book of Facts. (2006). Home accident deaths in the U.S., 1950-2003.

World Almanac \& Book of Facts. Retrieved February 1, 2007, from Ebscohost database.

Yoshida, K., \& Stephens, M. (2004). Living with rheumatoid arthritis. Strategies that support independence and autonomy in everyday life. Physiotherapy Theory \& Practice, 20, 221-231. 


\section{Author Information}

Grace S. Fisher, Ed.D., OTR/L*

Associate Professor of Occupational Therapy

Misericordia University

Dallas, PA 18612

Email: gfisher@misericordia.edu

Erin Bradley, MS, OT

Misericordia University graduate, 2008

Diane Costulas, MS, OT

Misericordia University graduate, 2008

Laura Kintner, MS, OT

Misericordia University graduate, 2008

Jodi Kozlevcar, MS, OT

Misericordia University graduate, 2008

Karla Mahonski, MS, OT

Misericordia University graduate, 2008

Keira McMenamin, MS, OT

Misericordia University graduate, 2008

Amanda Rompilla, MS, OT

Misericordia University graduate, 2008

Jillian Woods, MS, OT,

Misericordia University graduate, 2008

Keith Ewonishon, MS, OT

Misericordia University graduate, 2007

Jay Stine, Ph.D.

Assistant Professor of Mathematics

Misericordia University

* corresponding author 


\section{Appendix A}

Table 2

Mean Percent of Residences Rated "Safe" at Initial and Re-Assessment and Mean Improvement ( $=40)$

\begin{tabular}{|c|c|c|c|}
\hline Criterion & $\begin{array}{l}\text { Mean Percent } \\
\text { of Residences } \\
\text { Rated "Safe"- } \\
\text { Initial } \\
\text { Assessment }\end{array}$ & $\begin{array}{l}\text { Mean Percent } \\
\text { of Residences } \\
\text { Rated "Safe"- } \\
\text { Re-Assessment }\end{array}$ & $\begin{array}{l}\text { Mean } \\
\text { Improve- } \\
\text { ment }\end{array}$ \\
\hline $\begin{array}{l}\text { 1. There is a fire extinguisher present on every } \\
\text { frequently used level of the house or apartment. }\end{array}$ & 37.5 & 72.5 & 35.0 \\
\hline $\begin{array}{l}\text { 2. There is a functional smoke detector on the } \\
\text { ceiling in every level of the house or apartment } \\
\text { (and near all bedrooms). }\end{array}$ & 85.0 & 92.5 & 7.5 \\
\hline 3. Smoke detectors tested in last 6 months. & 90.0 & 97.5 & 7.5 \\
\hline $\begin{array}{l}\text { 4. There is a functional carbon monoxide detector } \\
\text { present on every level of the house or apartment. }\end{array}$ & 37.5 & 65.0 & 27.5 \\
\hline $\begin{array}{l}\text { 5. Carbon monoxide detectors tested within the } \\
\text { last } 6 \text { months. }\end{array}$ & 45.0 & 70.0 & 25.0 \\
\hline $\begin{array}{l}\text { 6. Portable heaters, ashtrays, candles, and other } \\
\text { fire sources are located away from flammable } \\
\text { objects. }\end{array}$ & 100.0 & 100.0 & 0 \\
\hline $\begin{array}{l}\text { 7. Flammable objects are located away from } \\
\text { stationary fire sources such as fireplaces, stoves, } \\
\text { or radiators. }\end{array}$ & 100.0 & 100.0 & 0 \\
\hline $\begin{array}{l}\text { 8. Flammable objects such as towels or curtains } \\
\text { are located away from the stove area, and are at } \\
\text { least } 12 \text { " from the baseboard or portable heater. }\end{array}$ & 97.5 & 97.5 & 0 \\
\hline $\begin{array}{l}\text { 9. Chimney sweeps are conducted according to } \\
\text { suggested time frames. }\end{array}$ & 85.0 & 92.5 & 7.5 \\
\hline $\begin{array}{l}\text { 10. One medical alert device is accessible in the } \\
\text { house, and may be reached without risk of injury. }\end{array}$ & 90.0 & 95.0 & 5.0 \\
\hline $\begin{array}{l}\text { 11. At least one cordless or accessible telephone } \\
\text { is on each level of the house. }\end{array}$ & 100.0 & 100.0 & 0 \\
\hline $\begin{array}{l}\text { 12. Emergency numbers are posted on or near the } \\
\text { telephone, or are easily accessible without risk of } \\
\text { injury. }\end{array}$ & 65.0 & 95.0 & 30.0 \\
\hline $\begin{array}{l}\text { 13. Flashlights are accessible, functional, and } \\
\text { may be reached without risk of injury. }\end{array}$ & 95.0 & 97.5 & 2.5 \\
\hline 14. Assistive devices are in accessible areas. & 100.0 & 100.0 & 0 \\
\hline $\begin{array}{l}\text { 15. Medications are stored in an accessible area } \\
\text { and are no older than the expiration date. }\end{array}$ & 97.5 & 100.0 & 2.5 \\
\hline $\begin{array}{l}\text { 16. All areas of the home are well maintained and } \\
\text { clean. }\end{array}$ & 97.5 & 100.0 & 2.5 \\
\hline $\begin{array}{l}\text { 17. First aid kit, with simple instructions, is } \\
\text { accessible and may be reached without risk of } \\
\text { injury. }\end{array}$ & 87.5 & 95.0 & 7.5 \\
\hline $\begin{array}{l}\text { 18. Major appliances such as microwave oven, } \\
\text { washer, dryer, and refrigerator may be assessed } \\
\text { without risk of injury. }\end{array}$ & 97.5 & 100.0 & 2.5 \\
\hline
\end{tabular}




\begin{tabular}{|c|c|c|c|}
\hline $\begin{array}{l}\text { 19. All outlets and switches have plate covers, so } \\
\text { no wiring is exposed, and are in easy reach. }\end{array}$ & 95.0 & 95.0 & 0 \\
\hline $\begin{array}{l}\text { 20. All cords are placed out of the flow of traffic } \\
\text { or safely covered. }\end{array}$ & 97.5 & 97.5 & 0 \\
\hline $\begin{array}{l}\text { 21. Cords are not attatched to walls or baseboards } \\
\text { with nails or staples. }\end{array}$ & 100.0 & 100.0 & 0 \\
\hline $\begin{array}{l}\text { 22. Cords are in good condition (not cracked or } \\
\text { frayed). }\end{array}$ & 100.0 & 100.0 & 0 \\
\hline $\begin{array}{l}\text { 23. Electrical cords and appliance cords are } \\
\text { located away from the sink and stove areas. }\end{array}$ & 97.5 & 100.0 & 2.5 \\
\hline $\begin{array}{l}\text { 24. Ground fault switches are present in } \\
\text { bathroom and kitchen outlets. }\end{array}$ & 57.5 & 62.5 & 5.0 \\
\hline $\begin{array}{l}\text { 25. Small electrical appliances are unplugged } \\
\text { when not in use. }\end{array}$ & 80.0 & 90.0 & 10.0 \\
\hline 26. Outlets do not appear to be overloaded. & 97.5 & 100.0 & 2.5 \\
\hline 27. The water temperature is 120 degrees & 82.5 & 92.5 & 10.0 \\
\hline $\begin{array}{l}\text { Fahrenheit or lower as tested in sink or tub. } \\
28 \text {. Floor surfaces are level with no more than } \\
1 / 4-1 / 2 \text { inch beveled transitions. }\end{array}$ & 95.0 & 97.5 & 2.5 \\
\hline 29. Carpeting is secure and level. & 95.0 & 95.0 & 0 \\
\hline $\begin{array}{l}\text { 30. If throw rugs are present, they have a slip- } \\
\text { resistant backing. }\end{array}$ & 67.5 & 85.0 & 17.5 \\
\hline $\begin{array}{l}\text { 31. Hallways, passageways, and stairways are } \\
\text { free of clutter. }\end{array}$ & 100.0 & 100.0 & 0 \\
\hline $\begin{array}{l}\text { 32. Hallways, passageways, and stairways } \\
\text { between rooms have lighting available. }\end{array}$ & 100.0 & 100.0 & 0 \\
\hline 33. Night lights are available in all areas. & 77.5 & 92.5 & 15.0 \\
\hline $\begin{array}{l}\text { 34. Indoor stairways have a secure railing on at } \\
\text { least one side. }\end{array}$ & 85.0 & 85.0 & 0 \\
\hline 35. Dials are labeled on stove. & 100.0 & 100.0 & 0 \\
\hline $\begin{array}{l}\text { 36. There is no excessive grease or clutter on or } \\
\text { around the stove area. }\end{array}$ & 100.0 & 100.0 & 0 \\
\hline $\begin{array}{l}\text { 37. Commonly used items are stored in } \\
\text { accessible locations and may be reached without } \\
\text { risk of injury. }\end{array}$ & 100.0 & 100.0 & 0 \\
\hline $\begin{array}{l}\text { 38. Garbage cans, pet bowls, and other objects } \\
\text { are not located in the walking path. }\end{array}$ & 97.5 & 100.0 & 2.5 \\
\hline $\begin{array}{l}\text { 39. There is a stable step stool or reaching stick } \\
\text { to access items above arms' reach. }\end{array}$ & 82.5 & 92.5 & 10.0 \\
\hline $\begin{array}{l}\text { 40. The countertops are free of rough or sharp } \\
\text { edges. }\end{array}$ & 100.0 & 100.0 & 0 \\
\hline $\begin{array}{l}\text { 41. There is adequate lighting over the stove and } \\
\text { sink areas, where food is cut or sliced. }\end{array}$ & 97.5 & 100.0 & 2.5 \\
\hline $\begin{array}{l}\text { 42. Refrigerator and freezer are at an acceptable } \\
\text { temperature and do not contain expired food. }\end{array}$ & 100.0 & 100.0 & 0 \\
\hline $\begin{array}{l}\text { 43. A slip-resistant mat or surface is outside all } \\
\text { bathtubs or showers. }\end{array}$ & 87.5 & 97.5 & 10.0 \\
\hline $\begin{array}{l}\text { 44. A slip-resistant mat or abrasive strips are in } \\
\text { all the bathtubs or showers. }\end{array}$ & 55.0 & 85.0 & 30.0 \\
\hline
\end{tabular}




\begin{tabular}{|c|c|c|c|}
\hline $\begin{array}{l}\text { 45. The following bathroom areas are accessible } \\
\text { and may be reached without significant risk of } \\
\text { physical injury: Tub, Sink, Toilet. }\end{array}$ & 100.0 & 100.0 & 0 \\
\hline $\begin{array}{l}\text { 46. A properly installed grab bar or other stable } \\
\text { surface is available and secure near the tub and } \\
\text { toilet. }\end{array}$ & 60.0 & 65.0 & 5.0 \\
\hline $\begin{array}{l}\text { 47. Closets and/or storage areas have lighting } \\
\text { available either inside or outside of the closet. }\end{array}$ & 85.0 & 95.0 & 10.0 \\
\hline $\begin{array}{l}\text { 48. Commonly used items within closets or } \\
\text { storage are accessible and may be reached } \\
\text { without risk of injury. }\end{array}$ & 97.5 & 100.0 & 2.5 \\
\hline $\begin{array}{l}\text { 49. Walk spaces near closets and storage areas } \\
\text { are free of clutter. }\end{array}$ & 95.0 & 100.0 & 5.0 \\
\hline $\begin{array}{l}50 . \text { The garage, if used, is accessible and has } \\
\text { adequate lighting. }\end{array}$ & 100.0 & 100.0 & 0 \\
\hline $\begin{array}{l}\text { 51. The attic, if used, is accessible and has } \\
\text { adequate lighting. }\end{array}$ & 97.5 & 97.5 & 0 \\
\hline $\begin{array}{l}\text { 52. All chemical products are stored in a safe } \\
\text { manner. }\end{array}$ & 95.0 & 97.5 & 2.5 \\
\hline $\begin{array}{l}\text { 53. Any weapons such as guns, knives, or } \\
\text { ammunition, are out of the view of visitors and } \\
\text { are in locked storage. }\end{array}$ & 95.0 & 95.0 & 0 \\
\hline $\begin{array}{l}\text { 54. Parking areas have lighting available and are } \\
\text { operable. }\end{array}$ & 97.5 & 100.0 & 2.5 \\
\hline 55. Parking areas are reasonably level. & 100.0 & 100.0 & 0 \\
\hline $\begin{array}{l}\text { 56. Walkways and sidewalks are clutter free and } \\
\text { level. }\end{array}$ & 100.0 & 100.0 & 0 \\
\hline $\begin{array}{l}\text { 57. Walkways and sidewalks have lighting } \\
\text { available and are operable. }\end{array}$ & 97.5 & 100.0 & 2.5 \\
\hline $\begin{array}{l}\text { 58. The doorbell and/or door-knocker is/are } \\
\text { functional. }\end{array}$ & 90.0 & 95.0 & 5.0 \\
\hline $\begin{array}{l}\text { 59. House numbers are visible on the home or } \\
\text { mailbox. }\end{array}$ & 87.5 & 97.5 & 10.0 \\
\hline $\begin{array}{l}\text { 60. Outside stairways, if present, have a secure } \\
\text { railing on at least one side. }\end{array}$ & 80.0 & 85.0 & 5.0 \\
\hline $\begin{array}{l}\text { 61. Entrances and doorways to home are free of } \\
\text { clutter and hazards. }\end{array}$ & 100.0 & 100.0 & 0 \\
\hline $\begin{array}{l}\text { 62. Outside porches or exit areas have working } \\
\text { lights available. }\end{array}$ & 100.0 & 100.0 & 0 \\
\hline $\begin{array}{l}\text { 63. Ramps, if present, are appropriately graded } \\
\text { and have accessible handrails which may be } \\
\text { reached without risk of injury. }\end{array}$ & 100.0 & 100.0 & 0 \\
\hline $\begin{array}{l}\text { 64. The bed height allows for getting in and out } \\
\text { safely. }\end{array}$ & 95.0 & 97.5 & 2.5 \\
\hline 65. Pathways in the bedroom are clear. & 97.5 & 97.5 & 0 \\
\hline 66. A phone is within reach of the bed. & 82.5 & 95.0 & 12.5 \\
\hline $\begin{array}{l}\text { 67. Lamps or light switches are within reach of } \\
\text { each bed. }\end{array}$ & 95.0 & 97.5 & 2.5 \\
\hline $\begin{array}{l}\text { 68. Ash trays, smoking materials, or other fire } \\
\text { sources are located away from beds or bedding. }\end{array}$ & 100.0 & 100.0 & 0 \\
\hline 69. Disaster kit readily available. & 15.0 & 30.0 & 15.0 \\
\hline
\end{tabular}




\begin{tabular}{|c|c|c|c|}
\hline $\begin{array}{l}\text { 70. Copy of current medication list in a } \\
\text { wallet/purse. }\end{array}$ & 65.0 & 80.0 & 15.0 \\
\hline $\begin{array}{l}\text { 71. Copy of medication in a sealed plastic bag } \\
\text { placed in disaster kit. }\end{array}$ & 35.0 & 52.5 & 17.5 \\
\hline 72. Extra month of medications available. & 82.5 & 87.5 & 5.0 \\
\hline $\begin{array}{l}\text { 73. Copy of physician's name and contact } \\
\text { information readily available. }\end{array}$ & 87.5 & 97.5 & 10.0 \\
\hline $\begin{array}{l}\text { 74. Emergency escape route planned for } \\
\text { evacuation. }\end{array}$ & 77.5 & 90.0 & 12.5 \\
\hline $\begin{array}{l}\text { 75. Extra food (non perishable) and water in } \\
\text { house to last seven days. }\end{array}$ & 80.0 & 82.5 & 2.5 \\
\hline $\begin{array}{l}\text { 76. Clothes and shoes available for immediate } \\
\text { use during disaster or emergencies. }\end{array}$ & 47.5 & 57.5 & 10.0 \\
\hline 77. Emergency car kit is available for evacuation. & 35.0 & 45.0 & 10.0 \\
\hline $\begin{array}{l}\text { 78. Plan for safe place in home in event of } \\
\text { tornado/hurricane/earthquake. }\end{array}$ & 85.0 & 90.0 & 5.0 \\
\hline
\end{tabular}

White $=$ No improvement (or at 100\% compliance at time of initial assessment and therefore no improvement needed.)

Light gray= Some improvement ( 1 to 14 percent improvement)

Dark gray $=$ Great improvement (15 to 35 percent improvement) 


\section{Appendix B}

Table 3

Increase in CHSA Scores per Participant: From Initial Assessment to Re-Assessments $(n=40)$

\begin{tabular}{|c|c|c|c|}
\hline Participant & Initial Safety Score & Re-assessment Score & Increase \\
\hline 27 & 76 & 97 & 21 \\
\hline 16 & 74 & 91 & 17 \\
\hline 26 & 76 & 92 & 16 \\
\hline 29 & 79 & 94 & 15 \\
\hline 11 & 77 & 91 & 14 \\
\hline 1 & 88 & 100 & 12 \\
\hline 12 & 83 & 95 & 12 \\
\hline 9 & 69 & 81 & 12 \\
\hline 30 & 88 & 99 & 11 \\
\hline 28 & 82 & 93 & 11 \\
\hline 17 & 75 & 85 & 10 \\
\hline 13 & 88 & 95 & 7 \\
\hline 10 & 82 & 89 & 7 \\
\hline 31 & 81 & 88 & 7 \\
\hline 2 & 91 & 97 & 6 \\
\hline 37 & 91 & 97 & 6 \\
\hline 5 & 89 & 95 & 6 \\
\hline 33 & 85 & 91 & 6 \\
\hline 7 & 72 & 78 & 6 \\
\hline 15 & 92 & 97 & 5 \\
\hline 23 & 91 & 96 & 5 \\
\hline 8 & 72 & 77 & 5 \\
\hline 39 & 95 & 99 & 4 \\
\hline 14 & 91 & 95 & 4 \\
\hline 18 & 87 & 91 & 4 \\
\hline 32 & 83 & 87 & 4 \\
\hline 4 & 97 & 100 & 3 \\
\hline 40 & 96 & 99 & 3 \\
\hline 36 & 92 & 95 & 3 \\
\hline 25 & 88 & 91 & 3 \\
\hline 19 & 80 & 83 & 3 \\
\hline 20 & 87 & 89 & 2 \\
\hline 34 & 86 & 88 & 2 \\
\hline 6 & 86 & 88 & 2 \\
\hline 3 & 96 & 97 & 1 \\
\hline 38 & 94 & 95 & 1 \\
\hline 35 & 83 & 84 & 1 \\
\hline 22 & 96 & 96 & 0 \\
\hline 24 & 91 & 91 & 0 \\
\hline 21 & 85 & 85 & 0 \\
\hline Mean Score & 85 & 92 & 6.4 \\
\hline
\end{tabular}

